\title{
Symbols of Power: The Firearm Paintings of Madjedbebe (Malakunanja II)
}

\author{
Sally K. May ${ }^{1}$ • Daryl Wesley ${ }^{2}$ - Joakim Goldhahn ${ }^{3}$ • \\ Mirani Litster ${ }^{4} \cdot$ Brad Manera $^{5}$
}

(C) The Author(s) 2017. This article is published with open access at Springerlink.com

\begin{abstract}
Depictions of firearms in Australian Aboriginal rock art provide a unique opportunity to archaeologically explore the roles that this type of material culture played in times of culture contact. From the earliest interactions with explorers to the buffalo shooting enterprises of the twentieth century-firearms played complex and shifting roles in western Arnhem Land Aboriginal societies. The site of Madjedbebe (sometimes referred to as Malakunanja II in earlier academic literature) in Jabiluka (Mirarr Country), offers the opportunity to explore these shifting roles over time with an unprecedented 16 paintings of firearms spanning the nineteenth and twentieth centuries. This rock art provides evidence for early firearms as objects of curiosity
\end{abstract}

\author{
Sally K. May \\ sallykmay@live.com.au \\ Daryl Wesley \\ daryl.wesley@gmail.com \\ Joakim Goldhahn \\ Joakim.goldhahn@lnu.se \\ Mirani Litster \\ mirani.litster@anu.edu.au \\ Brad Manera \\ brad.manera@anzacmemorial.nsw.gov.au
}

1 Place, Evolution and Rock Art Heritage Unit (PERAHU), Griffith Centre for Social and Cultural Research, Gold Coast campus, Southport, QLD 4222, Australia

2 Department of Archaeology, Flinders University, Adelaide, SA 5042, Australia

3 School of Cultural Sciences, Linnæus University, 39182 Kalmar, Sweden

4 Archaeology and Natural History, School of Culture, History and Language, The Australian National University, Canberra, ACT 0200, Australia

5 Anzac Memorial, Locked Bag 53, Darlinghurst, NSW 1300, Australia 
and threat to local groups, as well as evidence for later personal ownership and use of such weaponry. Moreover, we argue that the rock art suggests increasing incorporation of firearms into traditional cultural belief and artistic systems over time with Madjedbebe playing a key role in the communication of the cultural meanings behind this new subject matter.

Keywords Rock art · Arnhem land · Weapons · Firearms

\section{Introduction}

Firearms are one of the most universally recognized symbols of power, conflict and status in Western society. During periods of culture contact between so-called Western and Indigenous cultures, they represent not simple one-directional power relationships, but complex interactions, shifting value systems, and unexpected engagements with introduced technologies. In this paper we use a newly documented rock art assemblage of firearms painted at one of Australia's oldest occupation sites-Madjedbebe (formerly Malakunanja II), to explore the complex role that firearms played in Aboriginal society and the artist's possible motivations for depicting them in large numbers at this particular place.

From a global perspective, there are some well-investigated depictions of weaponry in rock art (including recent firearms) that represent encounters, especially during transition periods (e.g., Challis 2012; Dowson 1993; Keyser 1992, 2004; Wesley 2013). This rock art can provide rare insight into the lives of the artists and their communities and a "reverse gaze" from, for example, Indigenous people to colonizer/s and invaders (Ouzman 2003: 253), as with the famous Battle of the Little Big Horn in 1876 (e.g., Keyser 2004; Keyser and Klassen 2001; McCleary 2008; Michno 1997; Sundstrom 1989, 2004), but it is clear that in some instances cultural protocols within particular societies have limited how far artists could stray from the normative values of their society to further personal aspirations (e.g., Black Elk and Neihardt 1988; May 2008; Nabokov 1982). Other examples have highlighted how rock art can be extended to ideology and propaganda. For example, in his analysis of Bushman contact rock art in South Africa, Ouzman (2003: 11) suggests that "none of the 102 known rockpaintings of inter-group conflict from this area can be interpreted as the Bushmen losing the fight and in at least 60 of the conflict clusters the Bushmen are clearly shown as the victors." These examples illustrate the complexity of trying to ascertain historical truths from even the most recent of rock art.

A common thread weaving together depictions of weaponry in rock art traditions throughout the world is that novel technologies seem to attract the attention of artists. Frequently these technologies are depicted with great detail allowing for identification. Consequently, archaeologists working with rock art have used depicted weaponry not only to explore the historical contexts and outcomes of cultural encounters, but also to establish rock art chronologies through comparative methods (i.e., Abbott and Anderson-Whymark 2012; Anati 2004; Goldhahn 2015; Jones 2015; Keyser 2004; Keyser and Klassen 2001; Lewis 1988; Sundstrom 2004).

Many, if not all, of these rock art assemblages were created in turbulent times and contexts when value systems were being transformed. In many parts of Europe, for 
example, the introduction of copper and bronze technologies during the latter part of the third and the beginning of the second millennium BCE resulted in realistic and to scale depictions of weaponry in areas such as Valcamonica, Galicia, the British Isles, and Scandinavia (Goldhahn 2015, p. 115-119). As this weaponry became more common, the nature of the depictions altered or they disappeared. The tradition of depicting bronze weaponry on the British Isles, for example, was short-lived and limited to specific high status places and areas, such as Stonehenge in Wessex (Abbott and Anderson-Whymark 2012) and the Kilmartin region in Scotland (Jones 2015). A similar scenario occurs in Brittany (Twohig 1981) and Galicia in the northwest corner of the Iberian Peninsula (Bradley 1997; Santos Estevez 2008). In the Alps region and in northern Europe we also find weapons depicted to a realistic scale during the first initial phase of bronze metalwork but here these visual traditions continued subsequently in another form, mainly as stylized depictions of weaponry and attributes in the hands of armed warriors (e.g., Goldhahn 2015, see also Anati 2004; Bevan 2006; Horn 2013; Skoglund 2016; Vogt 2011).

We can see then that rock art assemblages can encode information relating to the role of material culture in society, including aspects of individual and group identity, status, and changes in the relationships between people and objects. It is within this framework that we interpret the firearm rock art at Madjedbebe.

\section{The Study Area: Madjedbebe}

Madjedbebe is located in Mirarr Country (Fig. 1) within the Jabiluka Leasehold, an area excised from Kakadu National Park as a uranium mining lease against the wishes of the Traditional Owners (O'Brien 2003, 2014). Thankfully the area is largely undisturbed by mining and retains all of the values for which Kakadu National Park was World Heritage listed. From 2011 to 2016 cultural sites were recorded in Jabiluka as a component of the Mirarr Gunwarddebim project - a collaboration between Aboriginal Traditional Owners and the Australian National University. To date, 528 rock art sites have been documented within Jabiluka, with analysis ongoing (e.g., Johnston et al. 2017; May et al. 2017; Wright et al. 2014; Wright et al. 2016).

Within Jabiluka lies a large rocky outcrop known as the Djawumbu massif or the Djawumbu-Madjawarrnja Complex (Fig. 2). The site of Madjedbebe is a northwest facing bluff face that forms part of this massif. Despite little shelter being provided by the bluff face, 1068 paintings, stencils, beeswax figures, and drawings have survived above the current ground level (May et al. 2017). Included in this remarkable assemblage are at least 36 paintings dating to the contact period. These contact paintings include an array of subjects from humans with "hands-on-hips" and "hats-on-heads" to European watercraft and smoking pipes. Most conspicuous, however, is the presence of 16 firearms painted across the length of the nearly 50-meter long shelter surface (see Fig. 2).

Madjedbebe features frequently in discussions concerning the timing of the colonization of Australia with recent re-investigations of the site positing that a 50-55 ka BP occupation is a "conservative" age estimate for the extent of 


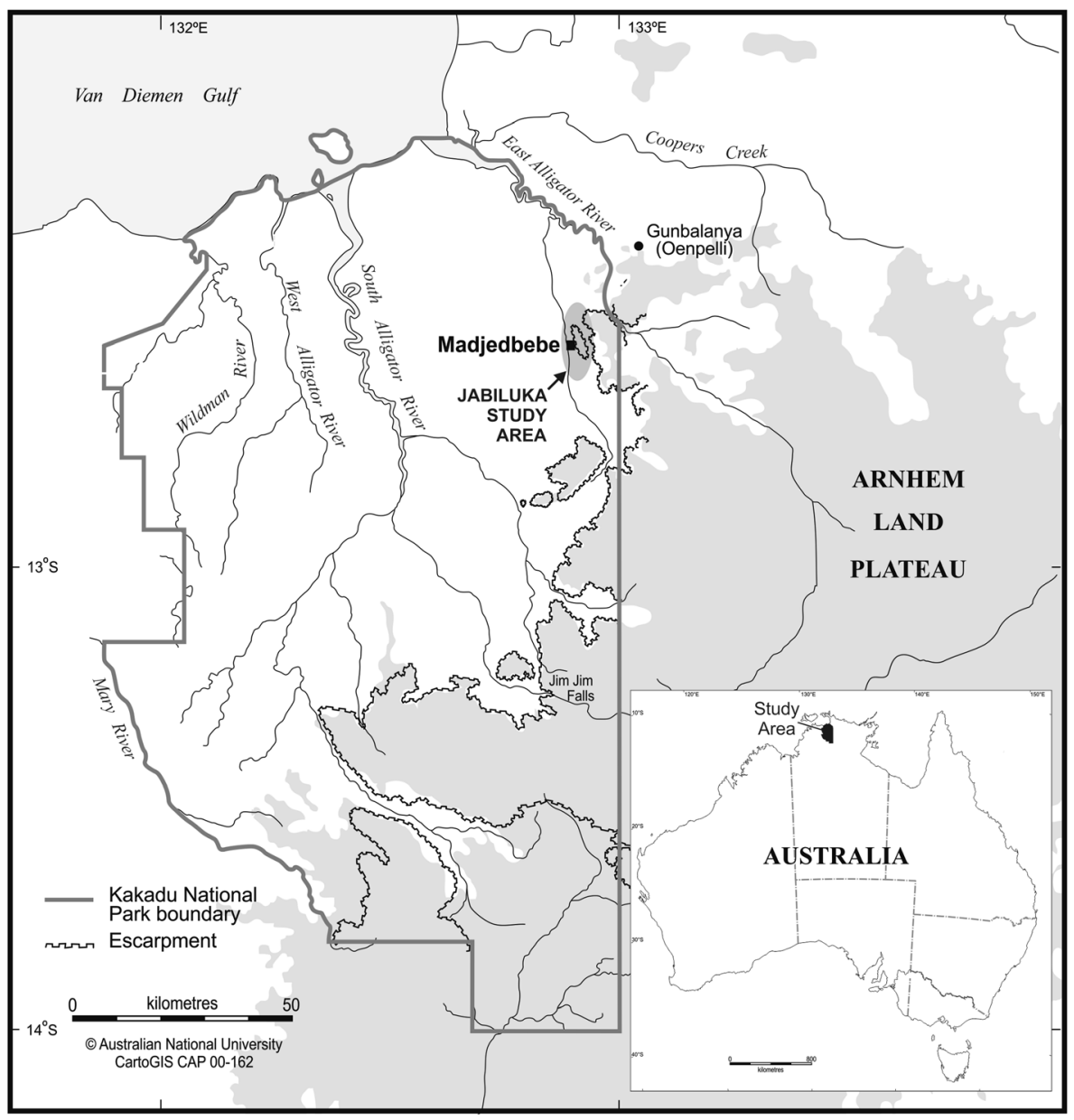

Fig. 1 Map showing the general location of the study area in northern Australia. The site Madjedbebe and the township of Gunbalanya are also indicated

occupation at the site (Clarkson et al. 2015). Previous excavations at the site returned dates of between $52 \pm 11 \mathrm{ka}$ and $61 \pm 13 \mathrm{ka}$, though these dates remain controversial (e.g., Allen and O’Connell 2003; Bowdler 1990; Clarkson et al. 2015; Hiscock 1990; Kamminga and Allen 1973; Roberts et al. 1990a:154, b, c; Roberts et al. 1994; Roberts et al. 1998:20). This early occupation at Madjedbebe stands in contrast to the rock art from the site that generally includes images and styles that are thought to be made during the last few thousand years (May et al. 2017). Madjedbebe is also one of the most prominent sites with contact rock art in Jabiluka, with only three other sites featuring introduced subject matter (though other more traditional subject matter is known to have been produced in the contact period as well). There is only one other site, out of 528 sites recorded, that has a depicted firearm, which clearly illustrates not only active ongoing use of Madjedbebe during the contact period but its deliberate selection as the place to 


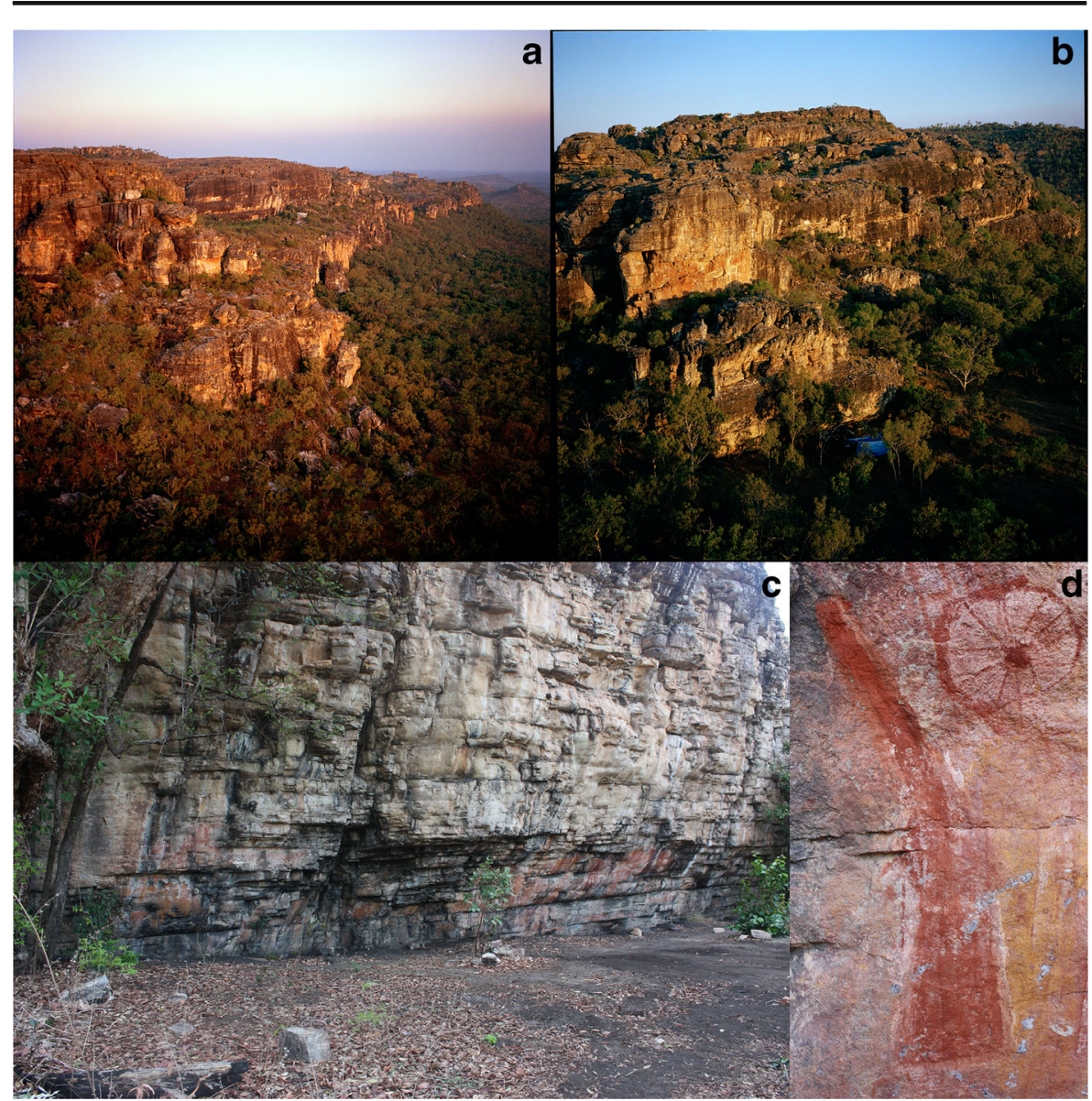

Fig. 2 a The Djawumbu Massif, Jabiluka, western Arnhem Land, b general photograph of the Madjedbebe site, $\mathbf{c}$ a view of the main painted panels at Madjedbebe, and $\mathbf{d}$ one of the firearm paintings from Madjedbebe (Motif 66)

illustrate new technologies in the region. The 16 firearm paintings, to be described in this article, add yet another layer of cultural complexity to this intriguing place.

\section{Firearms in Western Arnhem Land Rock Art}

While a long tradition of depicting weapons in rock art is evident across Arnhem Land (see, for example, Chaloupka 1993; Lewis 1988; Wesley 2013), newly introduced firearm motifs painted during the contact period illustrate the significance of these objects to local Aboriginal people and the complex relationship between object, artist, and society. Community members experienced firearms in many and varied ways including first contact and conflict with explorers and settlers during the early to mid-1800s and personal ownership of firearms as part of the buffalo industry from the late 1800s until the 1940s (Wesley 2013: 235). Few researchers have discussed the western Arnhem Land firearm paintings, with those that have offering little more than a 
passing mention (Brandl 1982; Chaloupka 1993; Edwards 1979; Jelinek 1989; Lewis 1988; May et al. 2010, 2013; Roberts and Parker 2003). The first detailed analysis of firearms from this region was undertaken by Wesley (2013). He analyzed 14 paintings of firearms from eight separate rock shelters and argued that the images were outward expressions of a multi-layered context for which the Indigenous narrative was no longer available (Wesley 2013: 246). He suggests, however, that they may provide insights into ownership, symbolic importance, and social status. Importantly, our new documentation of a single rock shelter, with more firearms painted than in his entire study area, provides a unique opportunity to further elaborate upon these initial insights.

\section{Historical Background}

Most relevant to our focus on firearms are the key interactions between western Arnhem Land Aboriginal groups and foreigners starting with Southeast Asian mariners from Makassar from the mid-seventeenth century, early European explorers and settlers to the area, and later involvement in the emerging buffalo shooting industry (Clark and May 2013; Levitus 1995). European exploration of northern Australia began in 1805 followed by the establishment of garrison settlements on the Tiwi Islands in 1824 and Cobourg Peninsula of northwestern Arnhem Land in 1829 through to 1849. The Cobourg Peninsula settlements were magnets for Aboriginal groups in northwestern Arnhem Land curious about the new people, introduced goods, and the technologies on display. Indeed, possession and display of firearms (muzzle loading and percussion-cap muskets and rifles), by the officers and soldiers at the Cobourg Peninsula settlements, was a source of curiosity for Aboriginal groups across the region (Mulvaney and Green 1992). The hiatus of European settlement ended with the formal establishment of Palmerston (Port Darwin) in 1870. Following this, Aboriginal groups had a series of negative experiences with firearms from several punitive expeditions and other parties pushing into western Arnhem Land with the Snider-Enfield rifle as the weapon of choice (Cross 2011: 240; Mulvaney 2004; NTTG 1875: 2, 1898: 3).

Growing trade and increased interaction in the late 1870s between European and Chinese settlers to the southeast of the region led to major shifts in Aboriginal economic and social systems and, as a result growing dependence on tobacco and alcohol, two key trade items (Forrest 1985: 5-6). Most significantly for the western Arnhem Land region was the emergence around 1891 of the buffalo shooting industry. This industry was based on the introduced Asian water buffalo from the earliest British settlements to the north and involved the lucrative international trade in buffalo hides. Aboriginal men, women, and children from the region participated in this industry by shooting, skinning, and salting large numbers of buffalo (Albrecht et al. 2009; Mulvaney 2004: 13; Robinson 2005: 893). It is during this time that firearms started to enter into Aboriginal use in large numbers for the first time.

Participation in these industries meant an important source of rations and access to new technologies such as firearms for Aboriginal people (Levitus 1995; Ritchie 1998; Robinson 2005). Yet, it is also clear that these groups retained traditional kinship ties and maintained cultural obligations with relatives and outside groups, ensuring the distribution of materials and goods widely in the region (Levitus 1995: Ritchie 1998; Robinson 2005; Robinson and Bowman 2002). A key historical influence for 
Aboriginal populations of the region was the establishment of Gunbalanya (Oenpelli) less than $30 \mathrm{~km}$ east of Madjedbebe. This settlement was later managed as a mission by the Church Missionary Society from 1923 (Cole 1975). On the whole, Aboriginal people in the western Arnhem Land region had increasing access to and shifting relationships with firearms over time-from the earliest engagements with explorers to the active buffalo shooting industry that relied on Aboriginal skills with firearms to thrive.

\section{Firearms in Western Arnhem Land}

All of the firearms at Madjedbebe are realistically depicted and most of the images show great detail, one is even depicted with a bullet in the barrel (Fig. 3) - this enables easy identification (Table 1). Rapid change in firearms technology is particularly dynamic in the late nineteenth century with various inventions that significantly change the appearance of the firing mechanisms. Coupled with these technological changes, it is important to recognize the history of firearm use in Arnhem Land in relation to the aforementioned political and economic activities of the nineteenth century. The type of firearms that are likely to be encountered in western Arnhem Land in the nineteenth and twentieth centuries is dictated by particular political and economic phases. Even if a certain technology is invented, there is a lag phase before it appears in remote areas and once arrived, these technologies are often used for longer periods and adapted for different purposes as the need arises. Overwhelmingly, Aboriginal people continued to use outdated firearms such as the Martini-Henry well into the early twentieth century (Wesley 2013).

The firearms identification methodology focusses on "long arms" and "short arms," which collectively refer to long- and short- barreled firearms intended to be held to the shoulder when fired. These can be either rifles, which are weapons with spiral grooves cut into the interior of the barrel to ensure the fired projectile spins, increasing both distance and accuracy, or smoothbore firearms with non-rifled barrels. A factor that creates some ambiguity for firearm identification is the composite nature of the modified Snider-Enfield from muzzle loading to breech loading which saw this rifle still retain its earlier nineteenth century form with the distinctive side hammer. This mass produced British Snider-Enfield made for an excellent second-hand inexpensive firearm for civilians, and was utilized in the late nineteenth century as a secondary firearm to the Martini-Henry in the buffalo-shooting industry. Both the Snider-Enfield rifle and the Martini-Henry have significant distinctive technological features that allow us to differentiate between them when depicted in rock art. As will be discussed, the firearms of Madjedbebe display varying numbers of identifiable features. Most,
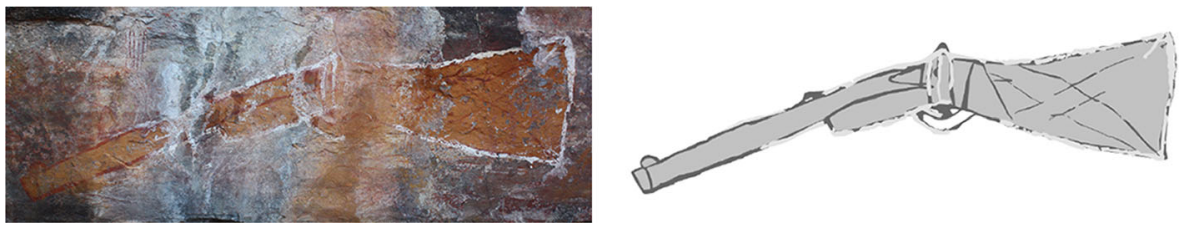

Fig. 3 Painting of a firearm from Madjedbebe showing a bullet in the barrel (Motif 673). Original photograph to the left and digital tracing to the right 
Table 1 Identifying characteristics of firearms (after Skennerton 1975)

\begin{tabular}{|c|c|c|}
\hline Period & Characteristics & $\begin{array}{l}\text { Firearm Types in the Northern } \\
\text { Territory }\end{array}$ \\
\hline $\begin{array}{l}\text { General firearm } \\
\text { characteristics of all time } \\
\text { periods }\end{array}$ & $\begin{array}{l}\text { Barrel, rear stock, trigger, trigger } \\
\text { guard, sling swivel, sling, butt } \\
\text { plate, foresight, rear sight, } \\
\text { fore-stock, bayonet lug, }\end{array}$ & $\begin{array}{l}\text { Firearms of all types may have these } \\
\text { characteristics from the } \\
\text { seventeenth century through to the } \\
\text { twentieth century. }\end{array}$ \\
\hline $\begin{array}{l}\text { Identifying characteristics of } \\
\text { firearms pre-1800-1870s }\end{array}$ & $\begin{array}{l}\text { Single barrel without separate breech, } \\
\text { "cock and hammer", flash pan and } \\
\text { frizzen, ramrod, likely to have no } \\
\text { fore or rear sight, match cord } \\
\text { (Macassan matchlock), trigger } \\
\text { hand steadying loop. }\end{array}$ & $\begin{array}{l}\text { Matchlocks (Asian), muskets (Dutch } \\
\text { and Portuguese), Brown Bess } \\
\text { musket varieties, percussion cap } \\
\text { musket and rifles }\end{array}$ \\
\hline $\begin{array}{l}\text { Identifying characteristics of } \\
\text { firearms from } 1870 \text { s-early } \\
\text { 1920s (including those } \\
\text { above) }\end{array}$ & $\begin{array}{l}\text { Variety of lever actions, hammer, tang } \\
\text { rear sight, rear sight in front of } \\
\text { breech area, "scalloped" or } \\
\text { "humped" breech loading area, } \\
\text { defined breech area, carbine (short } \\
\text { barrel and forestock), pump action, } \\
\text { compact breech area }\end{array}$ & $\begin{array}{l}\text { Martini-Henry, Snider-Enfield, } \\
\text { Winchester, Sharps Rifle, Henry } \\
\text { Rifle, break-open shot guns, } \\
\text { small-bore } .22 \text { rifles }\end{array}$ \\
\hline $\begin{array}{l}\text { Identifying characteristics of } \\
\text { firearms post-1900s }\end{array}$ & $\begin{array}{l}\text { Magazine (in front of the trigger } \\
\text { area), bolt action, pump action }\end{array}$ & $\begin{array}{l}\text { Lee-Enfield } .303 \text { SMLE, Mauser } \\
\text { pattern } 7.69 \mathrm{~mm} \text {, Winchester lever } \\
\text { action, shot guns (various), small } \\
\text { bore } .22 \text { rifles }\end{array}$ \\
\hline
\end{tabular}

however, could be confidently identified to a particular firearm type and time period (Fig. 4).

\section{Analysis: The Firearms of Madjedbebe}

A total of 16 firearm paintings were identified within the Madjedbebe rock art site complex, and a number of important examples are presented in Fig. 5. As can be seen in Tables 2 and 3, 14 of the 16 firearms could be assigned to a firearm type. These identifications reflect our best efforts at identification based on the information at hand-rock art and historical context. Depictions of firearms at Madjedbebe appear to range from the early British occupation period on the Cobourg Peninsula (1827-49) and from the period following the settlement of the Northern Territory in 1870 primarily associated with buffalo shooting (Fig. 6). There is significant overlap in the chronological periods owing to a number of factors including (a) the timing of historical explorations and settlements in northern Australia that limited the periods when culture contact was possible, (b) the firearms depicted can stay in circulation and use for long periods of time, and (c) some of the identification elements (i.e., hammer mechanism) of different firearm types persisted throughout the nineteenth century. We have, therefore, assigned firearm motifs to a chronological period depending on the characteristics depicted. As such, there are long periods spanning from 1827 (the earliest an encounter with European firearms could have occurred) to 1900 (which is reliably when firearms with hammer 


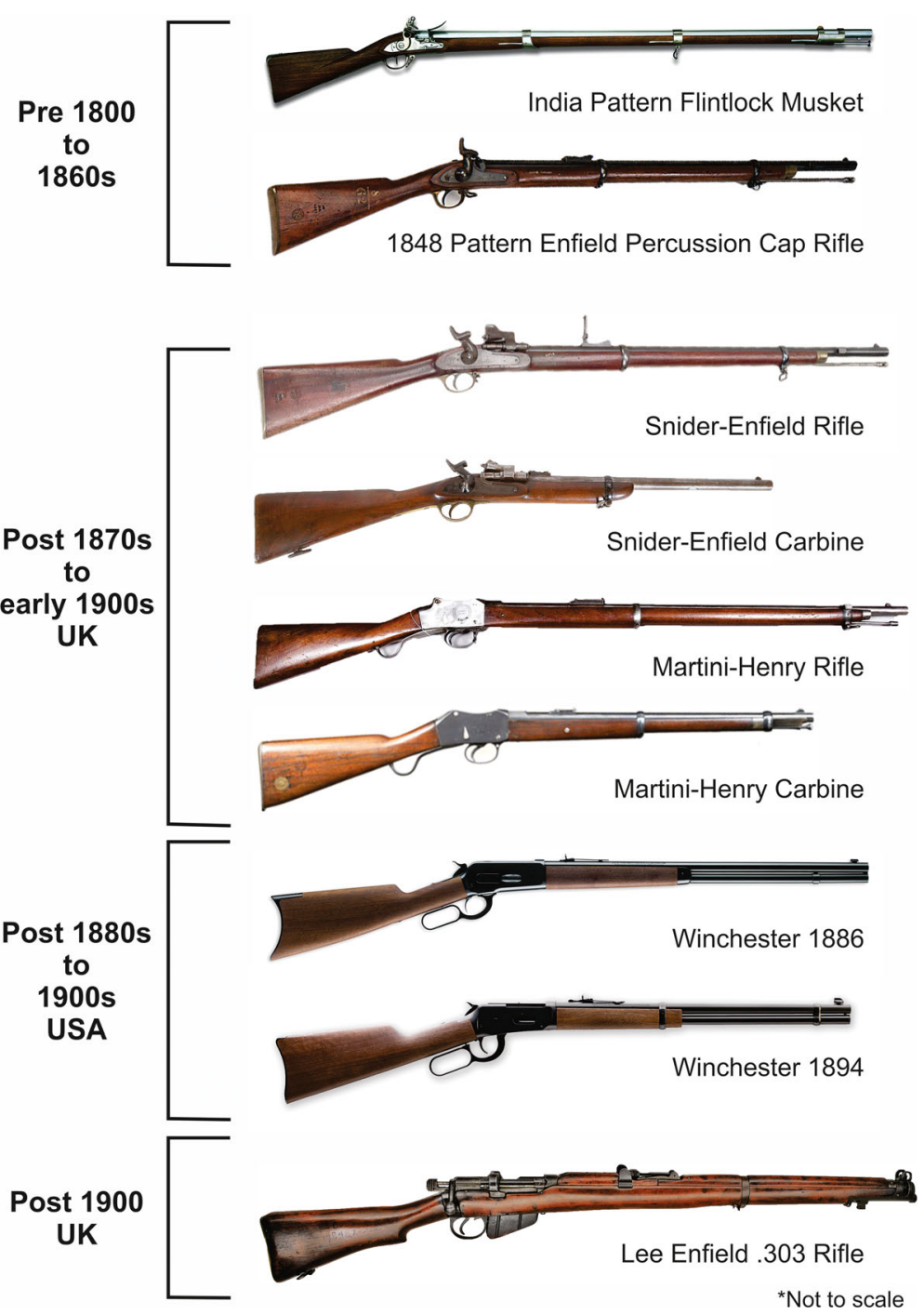

Fig. 4 Typical firearms available in the nineteenth and early twentieth centuries

mechanisms common to both muskets and the modified Snider-Enfield would have fallen out of common use). Despite these issues, the analysis illustrates continuity of Aboriginal engagement with firearms from their earliest introduction to the region and into the twentieth century.

In a number of the examples (Fig. 7), the artist has been able to highlight the breech area of the firearm by depicting it with lines - usually with two parallel lines- to emphasise the change from breech to rear stock - a commonly repeated element in these firearm paintings and others elsewhere (i.e., Wesley 2013). The moving parts of the firearms mechanisms are depicted mostly as the hammer, trigger, or a lever. This suggests a relatively high degree of familiarity with how the firearms worked as the artist noted that it was important to depict these functional characteristics. 

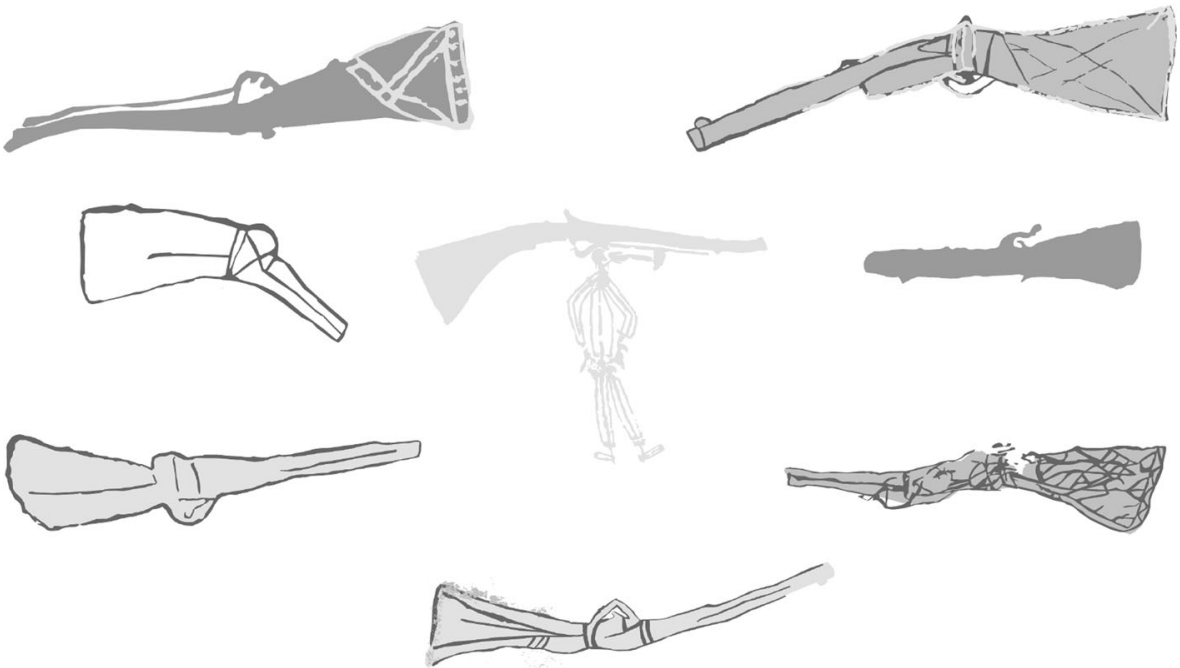

Fig. 5 Digital tracing of key paintings of firearms from Madjedbebe. Light $=$ white color, light grey = yellow color, dark grey = light red color, and dark = dark red color. Motifs depicted (clockwise from top right): 673, 957, 26, 42, 220, 209, 918 and 115 (center). Not to scale. Tracing by Joakim Goldhahn

Table 2 Description of each firearm painting from Madjedbebe

\begin{tabular}{|c|c|c|c|c|c|}
\hline $\begin{array}{l}\text { Motif } \\
\text { Number }\end{array}$ & Possible Firearm Type or Make & Era & Length $(\mathrm{cm})$ & Width(cm) & $\begin{array}{l}\text { Number of } \\
\text { Identifiable } \\
\text { Features }\end{array}$ \\
\hline 26 & Martini-Henry Carbine & $1880-1930$ & 73 & 22 & 5 \\
\hline 42 & Martini-Henry Carbine & $1880-1930$ & 63 & 18 & 6 \\
\hline 66 & Musket; Percussion Cap Rifle & $1827-1850$ & 38 & 16 & 5 \\
\hline 95 & Generic Firearm & $1827-1900$ & 59 & 9 & 3 \\
\hline 115 & Musket; Percussion Cap Rifle & $1827-1850$ & 31 & 9 & 5 \\
\hline 209 & Snider-Enfield Carbine & $1870-1900$ & 30 & 10 & 3 \\
\hline 220 & Musket or Percussion Cap Rifle & $1827-1850$ & 35 & 11 & 5 \\
\hline 469 & Snider-Enfield Carbine & $1870-1900$ & 31 & 10 & 3 \\
\hline 593 & Martini-Henry Rifle & $1880-1930$ & 55 & 14 & 2 \\
\hline 918 & Percussion Cap Rifle & $1827-1850$ & 83 & 25 & 5 \\
\hline 957 & Musket; Percussion Cap Rifle & $1827-1850$ & 45 & 10 & 5 \\
\hline 1054 & Martini-Henry Rifle & $1880-1930$ & 53 & 23 & 5 \\
\hline 1055 & $\begin{array}{l}\text { Musket; Percussion Cap } \\
\text { Carbine }\end{array}$ & $1827-1850$ & 51 & 13 & 3 \\
\hline 1058 & Generic Firearm & $1827-1900$ & 55 & 12 & 2 \\
\hline 1063 & Snider-Enfield Carbine & $1870-1900$ & 80 & 23 & 6 \\
\hline 673 & Snider-Enfield Carbine & $1870-1900$ & 65 & 15 & 8 \\
\hline
\end{tabular}


Table 3 Number of each firearm type identified at Madjedbebe

\begin{tabular}{lc} 
Type of Firearm & Number \\
\hline Muzzle Loading Firearm & 6 \\
Snider-Enfield & 4 \\
Martini-Henry & 4 \\
Generic Firearm & 2
\end{tabular}

The majority of the paintings are produced using the more complex method of solid background, outline, and decorative line infill pigments (64.7\%). Other painting methods included solid background and outline only (11.7\%), solid pigment only $(17.6 \%)$ and outline only (6\%). They were painted mostly in the bichromatic $(58.8 \%)$ manner, followed by monochromatic $(29.5 \%)$ and polychromatic $(11.7 \%)$ manners. Figure 8 clearly illustrates that the more recent firearm depictions, specifically those from the post-1870 period, include a greater variety of decorative elements. Pigment coloration distribution can be seen in Fig. 9 which illustrates that the combination of red and white pigments was the most commonly applied at the site. It also illustrates that the combination of red and white pigment was most common during the early period (1827-50) with the introduction of yellow pigment into the assemblage after 1870 .

Of the total depictions of firearms at Madjedbebe, eight (47\%) had decorative patterning infill, mostly in the breech or stock area of the firearm. This decorative infill was executed in several styles including " $\mathrm{X}$ " patterns, zigzag line pattern, square patterns, and parallel line patterns (see, for example, Figs. 2, 3 and 8).

The comparative distribution of rock art motif length and width versus actual firearm measurements illustrates that the artists were consistent with the dimensions of the firearms being depicted (Fig. 10). Although a number of the motifs were painted in near life-size dimensions, the motifs tended to be painted with over-exaggerated widths. In short, the artists were consistently exaggerating when it came to firearms - a theme continued from earlier rock art in this region (Chaloupka 1993; Taçon 1989a, b).

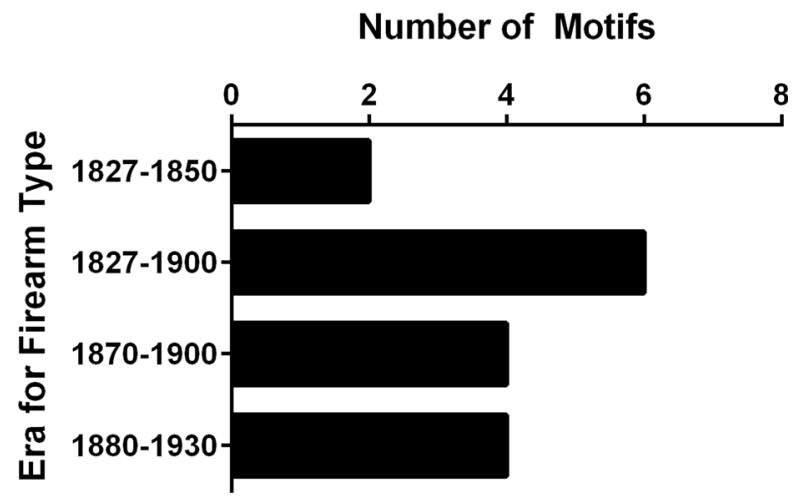

Fig. 6 Illustration of the spread of age periods associated with each firearm from Madjedbebe 


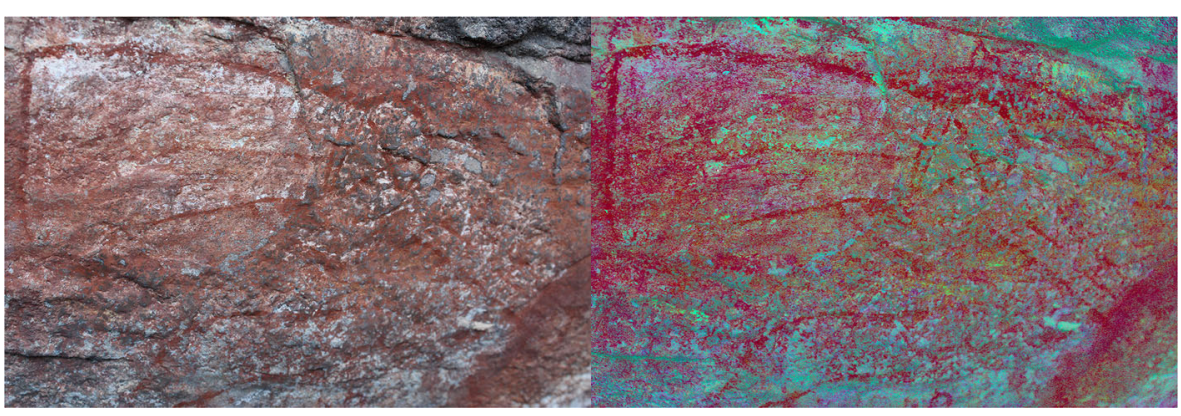

Fig. 7 Close-up of a painting of a firearm from Madjedbebe highlighting the breech area of the firearm (Motif 209). Original photograph on the left with digitally enhanced version on the right

\section{Discussion and Conclusion}

There is little doubt that the paintings of firearms at Madjedbebe were produced by Aboriginal artists. From the type of paint (naturally occurring ochres), to the methods and tools used to paint, and the subtle nod to other art styles produced in the region (:xray: art) - everything about these paintings suggests Aboriginal authorship. A key question then becomes - why would Aboriginal people select firearms as a key image type to depict repeatedly and over a long period of time at this site? The answer links into important questions relating to how the different levels of technical firearm knowledge and artistic stylistic choices illustrated by the paintings signals the shifting relationship between people, object, and identity.

In seeking answers to these questions there are some initial points to be made about the placement and distribution of contact rock art within Jabiluka. The contact rock art of introduced subject matter is restricted to just four known sites within Jabiluka, including only one other site with a depiction of a firearm (a Winchester lever-action rifle). Most, if not all, of these contact period sites are clearly connected to historically known traveling routes in the area (May et al. 2017). Further away from these routes there are only sporadic depictions of introduced subject matter. This distribution does not mean that rock art was not produced at other sites during the contact period, but

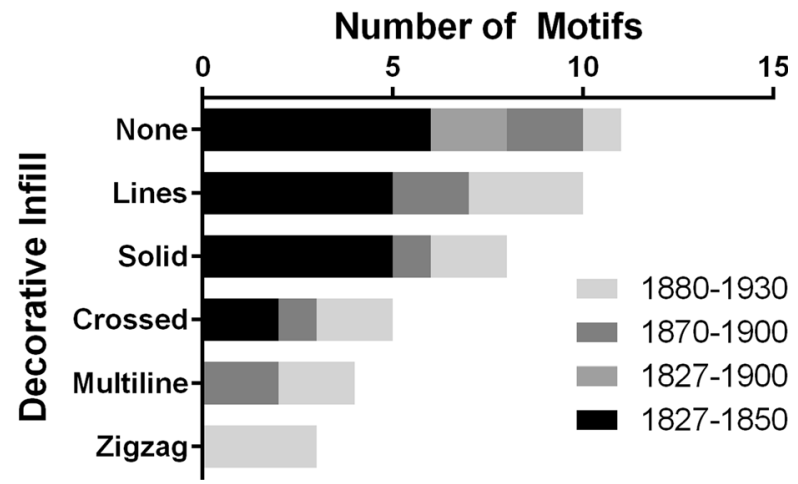

Fig. 8 Decorative element types used for each of the Madjedbebe firearms and their association with particular time periods 


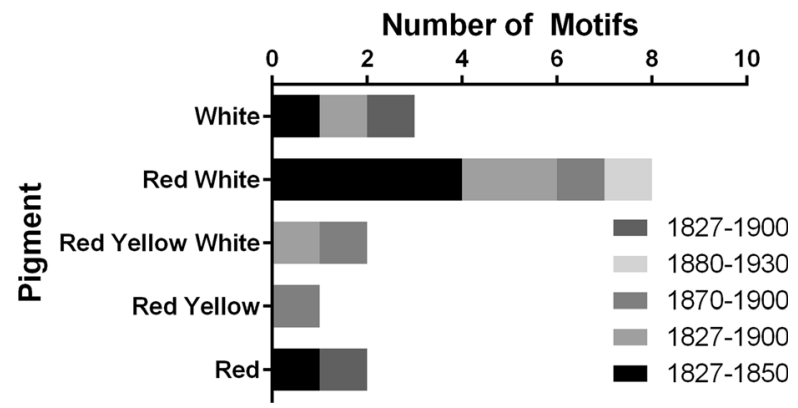

Fig. 9 Pigment combinations used to produce each firearm painting by proposed era of production at Madjedbebe

these artworks were made within styles that followed traditionally articulated protocols (e.g., Chaloupka 1993).

The identified firearms stretch over a 100-year period, from the earliest encounters during the first half of the nineteenth century up to the early twentieth century. The painted firearms testify to a growing familiarity with the newly introduced technology among Aboriginal people of western Arnhem Land. Of special interest is that the earliest paintings of firearms show less identifiable features than later ones (see Table 2), which could be interpreted as evidence that the artist was less acquainted with these firearms in the early contact period than in the more recent phase.

Another key element of these paintings is that more recent depictions of firearms show decoration and infill patterns which resemble the traditional "x-ray" art in the area. Firearms from the early contact period at Madjedbebe lack these details (see Fig. 8). As earlier research about rock art as well as contemporary bark painting has shown (e.g., Chaloupka 1993; Taçon 1987, 1989b; Taylor 1996), patterning is commonly used to express clan and kin group affiliations and identity as well as personal attachments and ownership to stories, places, and creation myths.

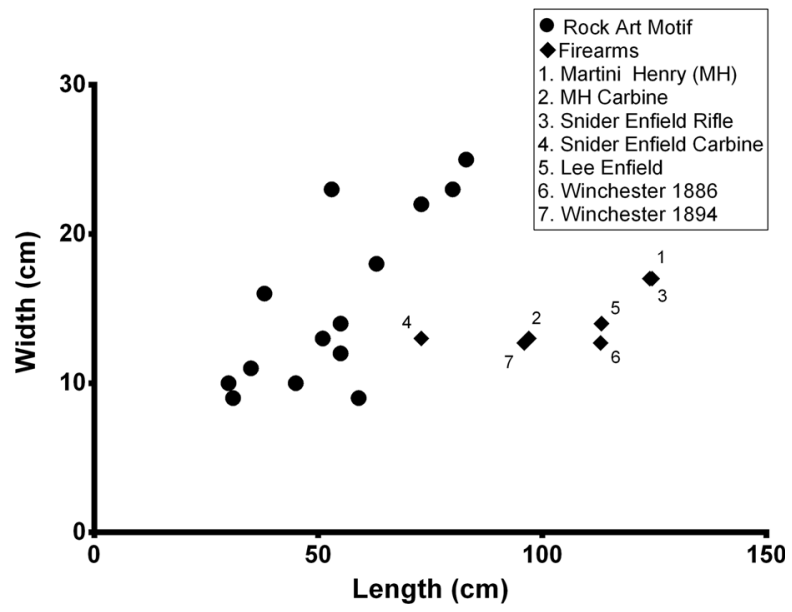

Fig. 10 Logarithmic plot of length and width of firearm motifs against actual firearm dimensions of rifles and carbines. Rifles used for this comparison include the Lee Enfield SMLE .303 and the Martini-Henry. Carbines used for this comparison include the Snider-Enfield, Martini-Henry, Winchester Model 1886, and the Winchester Model 1894 
A good example of this complexity is Taçon's (1989a, b) work on depictions of fish in rock art. He explains that the relationship between Aboriginal people and decorative "x-ray" paintings of fish was not simply a reflection of "fishing" but also revealed a complex relationship of instructions regarding the animal, and its totemic and spiritual symbolism. It is, therefore, likely that the increasing decorative infill and symbolism found within the Madjedbebe firearm paintings was intended to convey similar specific meanings of significance. For some reason unknown to us, communication of this information encoded in the firearm paintings was specifically chosen to be located at the site of Madjedbebe in Jabiluka.

Importantly in this context, a number of the Madjedbebe firearms are connected to buffalo which was considered an important totemic and economic animal species by Aboriginal people in Arnhem Land (cf. Berndt and Berndt 1970). Altman (1982, p. 282) noted that the newly introduced buffalo were integrated into contemporary Aboriginal mythology of the area with the buffalo's ears and horns being incorporated into depictions of the Rainbow Serpent (Ngalyod) and that the father of the Rainbow Serpent at that time was Nganaparru, the buffalo. Furthermore, Altman (1982) describes the complex customary traditions involved in hunting buffalo and the social distribution of this economic resource. He hypothesizes that the extent of the buffalo's integration into local customary belief systems had some antiquity, possibly going beyond five generations (Altman 1982: 283). These findings provide a strong case for a similar integration of the firearm into customary belief systems after its introduction which would include depiction in traditional systems of rock art.

A number of parallels can be made between the Great Basin Native American prestige hunt as discussed by McGuire and Hildebrandt (2005). McGuire and Hildebrandt (2005: 708) proposed that Great Basin prestige hunters participated in a complex signalling system that altered the character of subsistence, settlement, and work organization as well as affecting other members of the same social groups. As described above, similar signaling can be said to have occurred with the incorporation of Aboriginal labor in the buffalo shooting industry introduced to the East Alligator River region in the $1890 \mathrm{~s}$. Aboriginal men and women participated in the industry undertaking different tasks, men conducting the shooting, and women engaged in butchering and skinning of the buffalo (Levitus 1995). The complex decorative infill and re-engagement with these motifs, shown by secondary outlining and hand stencilling over the images, demonstrates the ability for Aboriginal people to gain power and prestige by using, owning, and then depicting in rock art the newly introduced firearms provided by the buffalo shooters.

But we believe there is even more to this story. The described patterns used on the firearm paintings are clearly more than a "simple to complex" artistic development, just as the paintings themselves illustrate more than an increasing fascination for the newly introduced technology. What we read into the changing depictions of firearms is an increasing encoding of information which goes beyond an appeal for new superior technologies or changing relationship between Aboriginal people and newcomers to their country.

The introduction of firearms impacted the status within Aboriginal society. The following quote from a letter between a local Scottish buffalo shooter and the anthropologist Baldwin Spencer illustrates this well. 
(Nipper) Murrakara had been buffalo shooting for F.A. Smith for years and always had his own way... Nipper shot a lot of buffalo's for Mr Smith and it was [to] Mr Smith's profit to look after Nipper, consequently Nipper done as he liked among the other natives, armed with a rifle there was no disputing his authority. (Paddy Cahill quoted in Mulvaney 2004: 120)

The introduction of firearms not only changed the relationship between people from different cultures, the access to this new technology also created new power relations among Aboriginal groups; especially between those who had access and those who did not. Murrakara's words show that the engagement of Aboriginal people with the Buffalo hunting industry also had profound consequences within societies in western Arnhem Land and that it, in a "Bourdieuian" sense, could act as a new form of "cultural capital." With archaeological debates surrounding the complex issue of intentionality (i.e., David 2004) in mind, we interpret a number of possibilities for deliberate and unintentional outcomes from firearms in Aboriginal society and their depiction in the rock art.

The Madjedbebe painted firearms are individual and unique creations. The individuality of the depictions as well as the restricted distribution of the contact rock art in Jabiluka, reflects a new role for the rock art where social display and positioning were chief. This suggestion of individual empowerment most likely provided a challenge to traditional values within local Aboriginal societies. Rights to paint in particular places and ownership of particular subject matter, for example, are tightly controlled in western Arnhem Land (see Taylor 1996). Only the appropriate individuals would have been granted permission to paint at this site in Jabiluka and these same individuals would have been restricted in the subjects they could depict (May 2006, 2008; Taylor 1996). The introduction of new technologies into the area and the depiction of these new objects in the rock art most likely created some unique problems for this restricted system. In other words, while the rights to paint particular plants and animals were clearly understood, new subject matter may have opened up opportunities for individuals to acquire a new subject for their rock art repertoire and to experiment with ways of painting them.

In conclusion, the value and understanding of the firearms painted at Madjedbebe, we argue, rests in the increasing encoding of information that can be detected over time through the decorated infill signaling cultural knowledge. The depicted firearms not only show a long time engagement with newcomers, they also illustrate changing relationships between western and Aboriginal cultures and an increasing reliance on each other. This is best demonstrated by the active role of Aboriginal people in the buffalo shooting industry, their use and ownership of firearms as part of this, and the artists' increasing familiarity with firearms over time. Yet, perhaps most interesting is the evidence we can see for shifting relationships between Aboriginal people in western Arnhem Land. Firearms played a key role in shifting power and status within Aboriginal groups and today rock art is providing evidence for this increased signaling of individual identity associated with the public display of social status.

Acknowledgments This research was funded by the Gundjeihmi Aboriginal Corporation and we would like to thank the Mirarr people for their ongoing support and collaboration. Special thanks to Yvonne Margarula and Justin O'Brien for setting up the Mirarr Gunwarddebim Project with us. We are very grateful to: Paul S.C. Taçon, Ines Domingo Sanz, Melissa Marshall, John Hayward, Iain Johnston and Janet Davill for their work 
helping to document this and other Mirarr rock art sites. Thanks are due to Energy Resources of Australia (ERA) for allowing us access to the Jabiluka Leasehold to undertake these surveys, the Natural Cultural Programs Unit (Kakadu National Park) for their time, assistance and ongoing support, and to the Northern Land Council and Aboriginal Areas Protection Authority for permits, maps and more. Many people have contributed to the Mirarr Gunwarddebim project in various ways and we thank you for your support. Finally, thanks to Michelle C. Langley for commenting on an early version of this manuscript and two anonymous reviewers for providing useful feedback.

Open Access This article is distributed under the terms of the Creative Commons Attribution 4.0 International License (http://creativecommons.org/licenses/by/4.0/), which permits unrestricted use, distribution, and reproduction in any medium, provided you give appropriate credit to the original author(s) and the source, provide a link to the Creative Commons license, and indicate if changes were made.

\section{References}

Abbott, M. and Anderson-Whymark, H. (2012). Stonehenge Laser Scan: Archaeological Analysis Report. English Heritage Research Report Series 32, London.

Albrecht, G., McMahon, C., Bowman, D. and Bradshaw, C. (2009). Convergence of culture, ecology, and ethics: management of feral swamp buffalo in northern Australia. Journal of Agricultural and Environmental Ethics 22(4): 361-378.

Allen, J. and O’Connell, J. (2003). The long and short of it: archaeological approaches to determining when humans first colonised Australia and new Guinea. Australian Archaeology 57: 5-19.

Altman, J. C. (1982). Hunting buffalo in north-central Arnhem land: a case of rapid adaptation among aborigines. Oceania 52(4): 274-285.

Anati, E. (2004). The Civilisations of Rocks: Valcamonica, a History for Europe. Edizioni del Centro, Capo di Ponte.

Berndt, R. M. and Berndt, C. H. (1970). Man, Land and Myth: The Gunwinggu people. Ure Smith, Sydney.

Bevan, L. (2006). Worshippers and Warriors: Reconstructing Gender and Gender Relations in the Prehistoric Rock Art of Naquane National Park, Valcamonica, Brescia, Northern Italy. BAR International Series 1485, Oxford.

Black Elk and Neihardt, J. (1988). Black Elk Speaks: Being the Life Story of a Holy Man of the Oglala Sioux. University of Nebraska Press, Lincoln.

Bowdler, S. (1990). 50,000-year-old site in Australia: is it really that old? Australian Archaeology 31: 93.

Bradley, R. (1997). Rock Art and the Prehistory of Atlantic Europe: Signing the Land. Routledge, London.

Brandl, E. J. (1982). Australian Aboriginal Paintings in Western and Central Arnhem Land, Temporal Sequences and Elements of Style in Cadell River and Deaf Adder Creek Art. Australian Institute of Aboriginal Studies, Canberra.

Challis, S. (2012). Creolisation on the nineteenth-century frontiers of southern Africa: a case study of the AmaTola "bushmen" in the maloti-Drakensberg. Journal of Southern African Studies 38(2): 265-280.

Chaloupka, G. (1993). Journey in Time: The World's Longest Continuing Art Tradition: The 50,000-Year Story of the Australian Aboriginal Rock Art of Arnhem Land. Reed New Holland, Sydney.

Clark, M. and May, M. eds. (2013). Macassan History and Heritage. ANU E Press, Canberra.

Clarkson, C., Smith, M., Marwick, B., Fullagar, R., Wallis, L., Faulkner, P., Manne, T., Hayes, E., Roberts, R., Jacobs, Z., Carah, X., Lowe, K., Matthews, J. and Florin, S. (2015). The archaeology, chronology and stratigraphy of Madjedbebe (Malakunanja II): a site in northern Australia with early occupation. Journal of Human Evolution 83: 46-64.

Cole, K. (1975). A History of Oenpelli. Nungalinya Publications, Darwin.

Cross, J. (2011). Great Central State: The Foundation of the Northern Territory. Wakefield Press, Adelaide.

David, B. (2004). Intentionality, agency and an archaeology of choice. Cambridge Archaeological Journal 14(1): $67-71$.

Dowson, T. (1993). Changing fortunes of southern African archaeology: comment on D. Mazel's "history." Antiquity 67(256): 641-644.

Edwards, R. (1979). Australian Aboriginal Art: The Art of the Alligator Rivers Region, Northern Territory. Australian Institute of Aboriginal Studies 15 (new series). Australian Institute of Aboriginal Studies, Canberra. 
Forrest, P. (1985). An outline of the history of the Gunbalanya locality. Unpublished report for FACTS Pty Ltd, Darwin.

Goldhahn, J. (2015). Engraved biographies: rock art and life-histories of bronze age objects. Current Swedish Archaeology 22: 97-136.

Hiscock, P. (1990). How old are the artefacts at Malakunanja II? Archaeology in Oceania 25: 122-124.

Horn, C. (2013). Weapons, fighters and combat: spears and swords in early bronze age Scandinavia. Danish Journal of Archaeology 2(1): 20-44.

Jelinek, J. J. (1989). The Great Art of the Early Australians: The Study of the Evolution and Role of Rock Art in the Society of Australian Hunters and Gatherers. Moravian Museum, Anthropos Institute, Brno.

Johnston, I., Goldhahn, J. and May, S. K. (2017). Dynamic figures of Jabiluka: Chaloupka's 4-phase theory and the question of variability within a rock art "style." In David, B., Taçon, P., Geneste, J.-M. and Delannoy, J.-J. eds., The Archaeology of Rock Art in Arnhem Land, Terra Australis, Australian National University, Canberra, forthcoming.

Jones, A. M. (2015). Rock art and the alchemy of bronze: metal and images in early bronze age Scotland. In Skoglund, P., Ling, J. and Bertilsson, U. eds., Picturing the Bronze Age, Oxbow Books, Oxford, pp. 7989.

Kamminga, J. and Allen, H. (1973). Alligator Rivers Environmental Fact Finding Study: Report of the Archaeological Survey. Australian Government, Canberra.

Keyser, J. D. (1992). Indian Rock Art of the Columbia Plateau. University of Washington Press, Seattle.

Keyser, J. D. (2004). Art of the Warriors: Rock Art of the American Plains. University of Utah Press, Salt Lake City.

Keyser, J. and Klassen, M. (2001). Plains Indian Rock Art. University of Washington Press, Seattle.

Levitus, R. (1995). Social history since colonisation. In Press, T., Lea, T., Webb, A. and Graham, A. eds., Kakadu: Natural and Cultural Heritage Management, ANCA and NARU, Darwin, pp. 64-93.

Lewis, D. (1988). The Rock Paintings of Arnhem Land, Australia: Social, Ecological and Material Culture Change in the Post-Glacial Period. BAR International Series 415, Oxford.

May, S. K. (2006). Karrikadjurren: Creating Community with an Art Centre in Indigenous Australia. Doctoral dissertation, Australian National University, Canberra.

May, S. K. (2008). Learning art, learning culture: art, education, and the formation of new artistic identities in Arnhem land, Australia. In Domingo Sanz, I., May, S. and Fiore, D. eds., Archaeologies of Art: Time, Place and Identity, Left Coast Press, Walnut Creek, pp. 171-194.

May, S. K., Taçon, P., Guse, D. and Travers, M. (2010). Painting history: indigenous observations and depictions of the "other" in northwestern Arnhem land, Australia. Australian Archaeology 71: 57-65.

May, S. K., Taçon, P., Paterson, A. and Travers, M. (2013). The world from Malarrak: depictions of southeast Asian and European subjects in rock art from the wellington range, Australia. Australian Aboriginal Studies 1: 45-56.

May, S. K., Taçon, P., Wright, D., Marshall, M., Goldhahn, J. and Domingo Sanz, I. (2017). The rock art of Madjedbebe (Malakunanja II). In David, B., Taçon, P., Geneste, J.-M. and Delannoy, J.-J. eds., The Archaeology of Rock Art in Arnhem Land, Terra Australis, Australian National University, Canberra, forthcoming.

McCleary, T. M. (2008). Ghosts on the Land: Apsaalooke (Crow Indian) Interpretations of Rock Art. Dissertations, ProQuest.

McGuire, K. R. and Hildebrandt, W. R. (2005). Re-thinking Great Basin foragers: prestige hunting and costly signaling during the middle archaic period. American Antiquity 70: 693-710.

Michno, G. F. (1997). Lakota Noon: The Indiana Narrative of Custer's Defeat. Mountain Press, Missoula.

Mulvaney, D. J. (2004). Paddy Cahill of Oenpelli. Aboriginal Studies Press, Canberra.

Mulvaney, J. and Green, N. (1992). Commandant of Solitude: The Journals of Captain Collet Barker 18291831. Melbourne University Press, Melbourne.

Nabokov, P. (1982). Two Leggings: The Making of a Crow Warrior. University of Nebraska Press, Lincoln.

Northern Territory Times and Gazette (NTTG). (1875). August 7, p. 2.

Northern Territory Times and Gazette (NTTG). (1898). December 23, p. 3.

O'Brien, J. (2014). No straight thing: experiences of the Mirarr traditional owners of Kakadu National Park with the world heritage convention. In Disko, S. and Tugendhat, G. eds., World Heritage Sites and Indigenous Peoples' Rights, IWGIA. Forest Peoples Programme and the Gundjeihmi Aboriginal Corporation, Copenhagen, pp. 313-338.

O'Brien, J. (2003). Canberra yellowcake: the politics of uranium and how aboriginal land rights failed the Mirrar people. Journal of Northern Territory History 14: 79.

Ouzman, S. (2003). Indigenous images of a colonial exotic: imaginings from bushmen in southern Africa. Before Farming 6(1): 239-256. 
Ritchie, D. J. (1998). Painful Wrench for a European Mind: Land Claims and Representations of History and Aboriginal Tradition in the Darwin Hinterland. Doctoral dissertation, Deakin University, Geelong.

Roberts, D. A. and Parker, A. (2003). Ancient Ochres: The Aboriginal Rock Paintings of Mt Borradaile. JB Books, Marlston.

Roberts, R., Jones, R. and Smith, M. (1990a). Thermoluminescence dating of a 50,000-year-old human occupation site in northern Australia. Nature 345: 153-156.

Roberts, R., Jones, R. and Smith, M. (1990b). Early dates at Malakunanja II: a reply to Bowdler. Australian Archaeology 3: 194-197.

Roberts, R., Jones, R. and Smith, M. (1990c). Stratigraphy and statistics at Malakunanja II: reply to Hiscock. Archaeology in Oceania 25: 125-129.

Roberts, R., Jones, R., Spooner, N., Head, M., Murray, A. and Smith, M. (1994). The human colonization of Australia: optical dates of 53,000 and 60,000 years bracket human arrival at deaf adder gorge, northern territory. Quaternary Science Reviews 13: 575-583.

Roberts, R., Yoshida, H., Galbraith, R., Laslett, G., Jones, R. and Smith, M. (1998). Single-aliquot and singlegrain optical dating confirm thermoluminescence age estimates at Malakunanja II rockshelter in northern Australia. Ancient TL 16: 19-24.

Robinson, C. J. (2005). Buffalo hunting and the feral frontier of Australia's northern territory. Social and Cultural Geography 6(6): 885-901.

Robinson, C. J. and Bowman, D. (2002). The getting of the Nganabbarru: observations and reflections on aboriginal buffalo hunting in northern Australia. Australian Geographer 33(2): 191-206.

Santos Estevez, M. (2008). A new proposal for the chronology of Atlantic rock art in Galicia (NW Iberian Peninsula). In Nash, G. and Children, G. eds., The Archaeology of Semiotics and the Social Order of Things, BAR International Series 1833, Oxford, pp. 141-152.

Skennerton, I. D. (1975). Australian Service Longarms. I. D. Skennerton, Margate.

Skoglund, P. (2016). Rock Art Through Time: Scandinavian Rock Carvings in the Bronze Age and Earliest Iron Age. Oxbow Books, Oxford.

Sundstrom, L. (1989). Rock Art of the Southern Black Hills: A Contextual Approach. University of Kansas, Lawrence.

Sundstrom, L. (2004). Storied Stones: Indian Rock Art in the Black Hill County. University of Oklahoma Press, Norman.

Taçon, P. S. C. (1987). Internal-external: a re-evaluation of the "x-ray" concept in western Arnhem land. Rock Art Research 4(1): 36-50.

Taçon, P. S. C. (1989a). From the "dreamtime" to the present: the changing role of aboriginal rock paintings in western Arnhem land, Australia. The Canadian Journal of Native Studies 9(2): 317-339.

Taçon, P. S. C. (1989b). From Rainbow Snakes to "X-Ray" Fish: The Nature of the Recent Rock Painting Tradition of Western Arnhem Land, Australia. Doctoral dissertation, Australian National University, Canberra.

Taylor, L. (1996). Seeing the Inside: Bark Painting in Western Arnhem Land. Clarendon Press, Oxford.

Twohig, E. S. (1981). The Megalithic Art of Western Europe. Clarendon Press, Oxford.

Vogt, D. (2011). Rock Carvings in Østfold and Bohuslän, South Scandinavia: An Interpretation of Political and Economic Landscapes. Institute for Comparative Research in Human Culture, Novus Forlag, Oslo.

Wesley, D. (2013). Firearms in rock art of the northern territory. Rock Art Research 30(2): 235-237.

Wright, D., May, S. K., Taçon, P. and Stephenson, B. (2014). A scientific study of a new cupule site in Jabiluka, western Arnhem land. Rock Art Research 31(1): 91-100.

Wright, D., Langley, M., May, S. K., Johnston, I. and Allen, L. (2016). Painted shark vertebrate beads from the Djawumbu-Madjawarrnja complex, western Arnhem land. Australian Archaeology 82(1): 43-54. 